
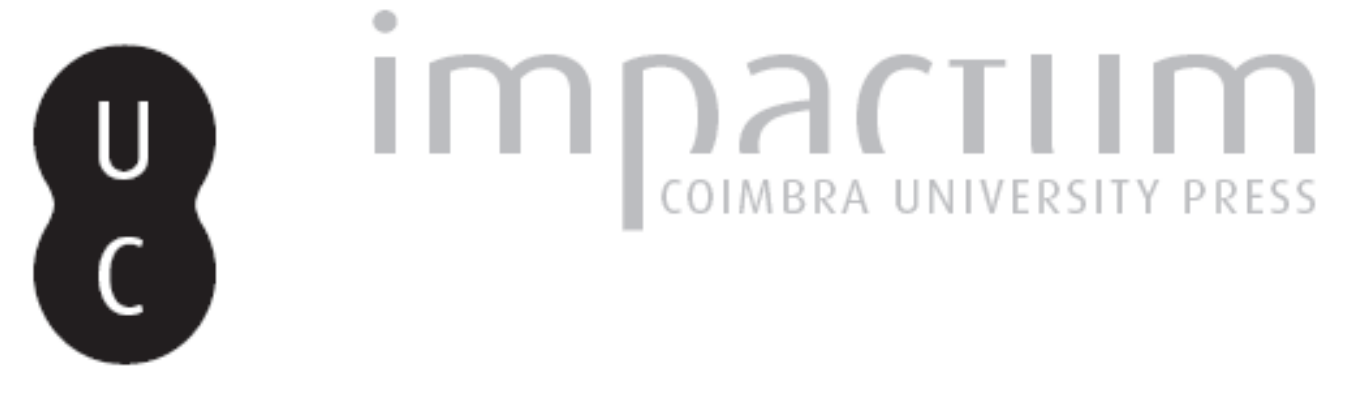

\title{
A Casa de Aveiro: poder e património
}

\section{Autor(es): Mata, Cristóvão}
Publicado por: Faculdade de Letras da Universidade de Coimbra, Instituto de História Económica e Social

URL persistente:

URI:http://hdl.handle.net/10316.2/33487

DOI:

DOI:http://dx.doi.org/10.14195/0870-4147_44_13

Accessed : $\quad$ 26-Apr-2023 11:00:41

A navegação consulta e descarregamento dos títulos inseridos nas Bibliotecas Digitais UC Digitalis, UC Pombalina e UC Impactum, pressupõem a aceitação plena e sem reservas dos Termos e Condições de Uso destas Bibliotecas Digitais, disponíveis em https://digitalis.uc.pt/pt-pt/termos.

Conforme exposto nos referidos Termos e Condições de Uso, o descarregamento de títulos de acesso restrito requer uma licença válida de autorização devendo o utilizador aceder ao(s) documento(s) a partir de um endereço de IP da instituição detentora da supramencionada licença.

Ao utilizador é apenas permitido o descarregamento para uso pessoal, pelo que o emprego do(s) título(s) descarregado(s) para outro fim, designadamente comercial, carece de autorização do respetivo autor ou editor da obra.

Na medida em que todas as obras da UC Digitalis se encontram protegidas pelo Código do Direito de Autor e Direitos Conexos e demais legislação aplicável, toda a cópia, parcial ou total, deste documento, nos casos em que é legalmente admitida, deverá conter ou fazer-se acompanhar por este aviso.

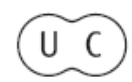




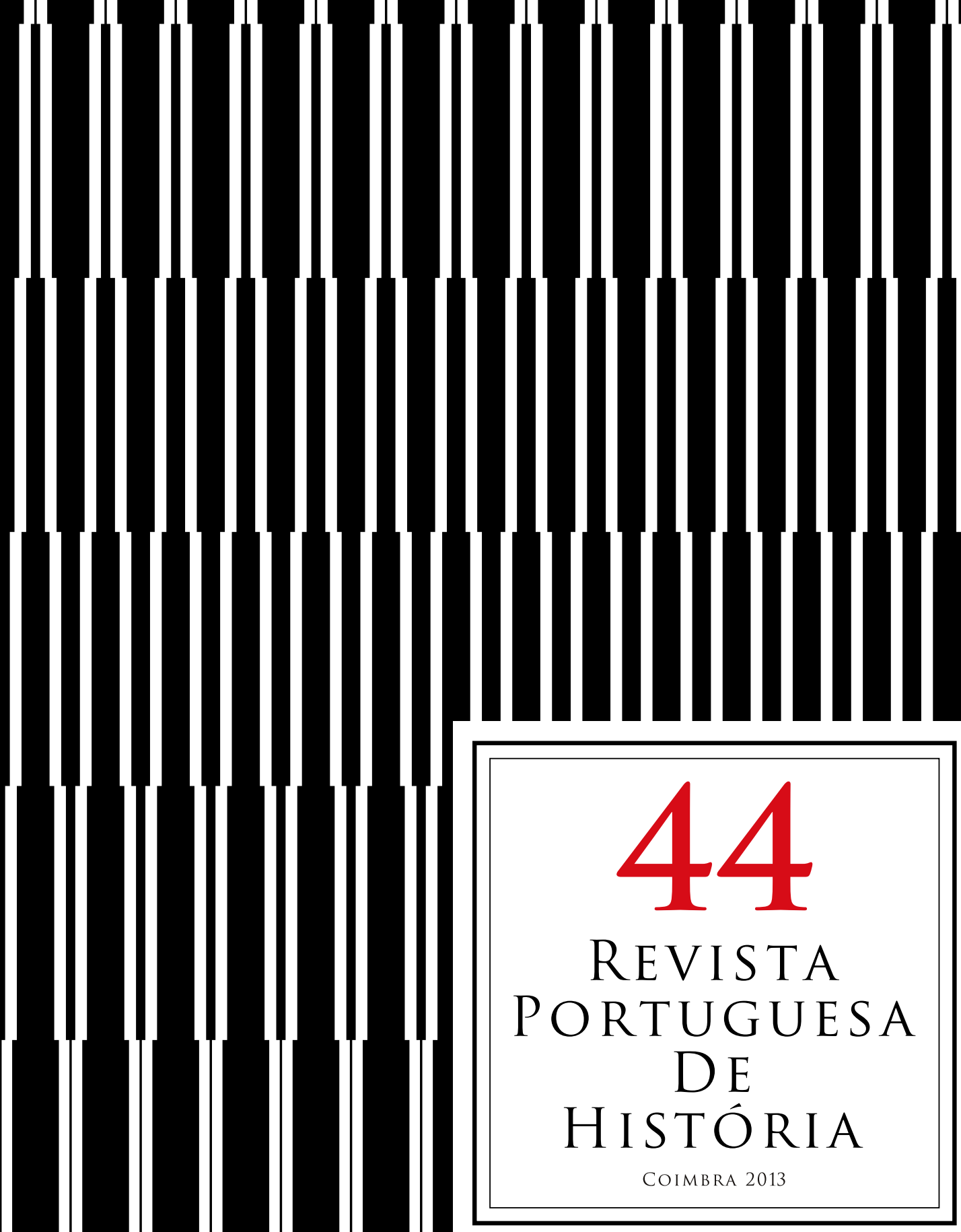




\title{
A Casa de Aveiro: poder e património
}

\author{
CRISTÓvão MatA \\ Doutorando do $3^{\circ}$ ciclo em Altos Estudos em História - Época Moderna \\ Universidade de Coimbra \\ cristovaomat@hotmail.com
}

\section{Resumo:}

Pretendemos com o presente artigo fazer uma incursão sobre o regime senhorial em Portugal durante a Época Moderna, tomando como objecto de estudo a Casa de Aveiro. O nosso objectivo é o de apresentar alguns dados relativos à efectiva dimensão dos poderes jurisdicionais dos duques sobre as suas terras, mas sobretudo abordar o seu património material em função da natureza e das características dos principais núcleos de bens, numa perspectiva que ofereça uma imagem de conjunto sobre esta Casa aristocrática.

\section{Palavras chave:}

Antigo Regime; Nobreza; Casa de Aveiro; Bens da Coroa; Bens das ordens.

\section{Abstract:}

With this article we pretend to make an incursion on the manorial regime in Portugal during the Early Modern Period, taking as subject the House of Aveiro. Our aim is to present some clues regarding the actual dimension of the jurisdictional powers of the Dukes on their lands, but mostly address their material assets depending on the nature and characteristics of the main centers of goods, by a perspective that offers a global picture of this aristocratic house.

\section{Keywords:}

Old Regime; Nobility; House of Aveiro; Crown assets; Military Orders assets. 
As considerações que se apresentam nas páginas seguintes inserem-se num projecto de estudo que, inspirado em trabalhos anteriores ${ }^{1}$, pretendemos desenvolver sobre a Casa de Aveiro. Foca, portanto, a problemática do regime senhorial durante a Época Moderna, que na realidade se traduzia na partilha do poder e da autoridade régia com várias entidades senhoriais - em meados do século XVII, por exemplo, apenas $30 \%$ das terras se encontravam sob a jurisdição do rei (exceptuando-se as que pertenciam às três ordens militares, cujo senhorio jurisdicional ainda não se encontrava plenamente incorporado na Coroa), face a 58\% de senhorios leigos e eclesiásticos. Não obstante a expressividade dos donatários na teia das relações entre poder e território, tal como em Espanha ${ }^{2}$, só muito tardiamente se animou o interesse da historiografia portuguesa pelo regime senhorial da Época Moderna ${ }^{3}$, tendo sido desde então desenvolvidos diversos estudos sobre os senhorios eclesiásticos e leigos ${ }^{4} \mathrm{e}$ as suas relações com os respectivos donatários ${ }^{5}$. Nestas circunstâncias, tem sido reconhecida a importância simbólica que revestia os senhorios jurisdicionais no

1 Cristóvão Mata, O concelho de Penela durante o Antigo Regime: um olhar sobre o poder local (1640-1834), Dissertação de mestrado em História Moderna: Poderes, Ideias e Instituições, Coimbra, Faculdade de Letras - Universidade de Coimbra, 2012.

2 Foi Dominguez Ortiz quem, na década de 1970, protagonizou o primeiro esforço de compreensão da nobreza espanhola. A primeira síntese sobre a nobreza foi elaborada por Soria Mesa, que entre outros aspectos focou os mecanismos de ascensão social. Desde então, entre diversos autores que se poderiam enunciar, Yun Casalillo estudou a gestão do património nobiliárquico e os correspondentes problemas financeiros; Eiras Roel apresentou as diferentes tipologias de senhorios e a hierarquização dos principais donatários durante o século XVIII; Saavedra Fernández analisou a natureza e a tipologia das rendas auferidas, os conflitos senhoriais e a administração dos estados senhoriais. Em todo o caso, continua a faltar uma visão de conjunto da nobreza espanhola - cf. Anastacio Santos Iglesias Blanco, La Casa de Amarante. Siglos XVI-XIX, Dissertação de Doutoramento em História, Santiago de Compostela, 2008, p. 1-6.

3 Nuno Gonçalo Monteiro, "Poder senhorial, estatuto nobiliárquico e aristocracia" in José Mattoso, História de Portugal, vol. 4, António Manuel Hespanha (Coord.), O Antigo Regime, Lisboa, Editorial Estampa, 1998, p. 304 e 308.

4 Fernando Taveira da Fonseca, A Universidade de Coimbra (1700-1771). Estudo social e económico, Coimbra, BGUC, 1992; Maria Paula Marçal Lourenço, A Casa e o Estado do Infantado, 1654-1706: formas e práticas administrativas de um património senhorial, Lisboa, JNICT, 1995; Margarida Sobral Neto, Terra e Conflito. Região de Coimbra (1700-1834), Viseu, Palimage, 1997; Mafalda Soares da Cunha, A Casa de Bragança, 1560-1640. Práticas senhoriais e redes clientelares, Lisboa, Estampa, 2000; Fátima Farrica, Poder sobre as periferias. A Casa de Bragança e o governo das terras do Alentejo (1640-1668), Évora, Colibri, 2011.

5 Maria Helena da Cruz Coelho e Joaquim Romero Magalhães, O poder concelhio: das origens às cortes Constituintes. Notas de história social, Coimbra, CEFA, 1986; César Oliveira (Org.), História dos Municípios e do Poder Local, Lisboa, Temas e Debates, 1996; e Mafalda Soares da Cunha e Teresa Fonseca (Ed.), Os Municípios no Portugal Moderno. Dos forais manuelinos às reformas liberais, Évora, Colibri, 2005. 
âmbito da modelação do estrato nobiliárquico ${ }^{6}$, mas sobre a efectiva dimensão prática destes poderes parece haver o consenso de que ainda pouco se sabe, recorrendo-se por isso às informações existentes para a Idade Média e para o Antigo Regime tardio ${ }^{7}$.

Os poderes jurisdicionais de um senhor localizavam-se nos espaços intermédios, na jurisdição de segunda instância, traduzindo-se localmente em direitos expressamente recebidos «suscetíveis» de interferir na composição das câmaras ${ }^{8}$ e no provimento do oficialato local, uma base social para a formação de redes clientelares. É, de facto, neste ponto que se levantam mais dúvidas, pois à uniformidade dos poderes jurisdicionais originalmente garantida pelas doações genéricas facilmente se podia substituir, mediante doações específicas, a heterogeneidade dos mesmos poderes dos donatários ${ }^{9}$. Por outro lado, a proximidade física dos donatários às suas terras podia significar um controlo apertado sobre as vereações, ou até uma forte capacidade de interferir nos assuntos locais, mas «a distância terá condicionado o exercício do poder senhorial» ${ }^{10}$.

Contudo, este parece ter sido o aspecto que no final do Antigo Regime menos ânimos exaltou. Em virtude das leis de 1790 e 1792, as faculdades políticas e administrativas das entidades senhoriais encontravam-se em fase avançada do seu processo de decomposição. Em 1811, por exemplo, somente 30\% das câmaras estavam sujeitas à jurisdição senhorial e apenas 18 juízes de fora (num total de 168) eram apresentados por donatários ${ }^{11}$. No âmbito dos movimentos anti-senhoriais, para o Mosteiro de Alcobaça esta perda de poder significava, por exemplo, ter de deparar-se com uma viva contestação protagonizada pelos próprios governos das suas terras ${ }^{12}$. Mas relativamente às causas que inspiravam

6 Nuno Gonçalo Monteiro, "Poder senhorial ...", cit., p. 305.

7 Mafalda Cunha Soares, "Poderes locais nas áreas senhoriais (séculos XVI-1640)" in Fernando Taveira da Fonseca (Coord.), O Poder Local em Tempos de Globalização: uma história e um futuro, Coimbra, IUC, p. 97-100.

8 Nuno Gonçalo Monteiro, "Poder senhorial ...", cit., p. 305-308.

9 Mafalda Soares da Cunha, "Relações de poder, patrocínio e conflitualidade. Senhorios e municípios (século XVI-1640)" in Mafalda Soares da Cunha e Teresa Fonseca (Ed.), Os Municípios..., cit., p. 90-91.

${ }^{10}$ Margarida Sobral Neto, "Senhorios e concelhos na época moderna: relações entre dois poderes concorrentes" in Mafalda Soares da Cunha e Teresa Fonseca (Ed.), Os Municípios..., cit., p. 154.

${ }^{11}$ Nuno Gonçalo Monteiro, "Poder senhorial ...”, cit., p. 308-313.

${ }^{12}$ Nuno Gonçalo Monteiro, Elites e Poder: entre o Antigo Regime e o Liberalismo, Lisboa, ICS, 2012, p. 215-399. 
os movimentos anti-senhoriais, eram mais os abusos dos donatários em matéria de cobrança de tributos e não tanto a questão das jurisdições ${ }^{13}$.

Falta, portanto, uma visão panorâmica sobre as entidades senhoriais do Portugal Moderno que, por um lado, ofereça uma imagem das efectivas práticas jurisdicionais e, por outro, caracterize o património de que se compunham, reportando-se tanto à natureza dos bens como à lua localização geográfica. Com efeito, no que diz respeito ao senhorialismo leigo, há importantes estudos sobre casas aristocráticas, como a de Bragança ou a do Infantado, mas estes focaram essencialmente as práticas jurisdicionais e administrativas e a gestão doméstica das casas. Do mesmo modo, o conhecimento que temos sobre a natureza dos bens que compunham o património da nobreza, embora importante, reporta-se a uma fase tardia do Antigo Regime português ${ }^{14}$.

O que propomos concretizar nas páginas que se seguem é uma abordagem à Casa de Aveiro enquanto «conjunto coerente de bens simbólicos e materiais» ${ }^{15}$, analisando-a numa perspectiva que acompanhe a configuração do seu património desde a sua constituição à definitiva incorporação na Coroa. Pretendemos descrever a localização geográfica dos seus bens e, simultaneamente, apresentar os traços que distinguiam os dois principais núcleos compostos por bens da Coroa. Pesem embora as dificuldades que obstam a uma conceptualização inequivocamente delimitada deste termo, tomamos como definição «todos os bens concedidos e confirmados em vida ${ }^{16}$. Mais especificamente, debruçar-nos-emos sobre o conjunto patrimonial formado pelas terras e bens do Infantado ${ }^{17}$ e das ordens militares concedidas ao duque de Coimbra D. Jorge de Lencastre, filho ilegítimo do rei D. João II.

A circunscrição da nossa abordagem a este campo justifica-se, primeiramente, pelo forte peso que a nível global estes bens detinham no cômputo geral das rendas da Casa de Aveiro: quando, em média, os bens da Coroa e ordens

${ }^{13}$ Margarida Sobral Neto, Terra e Conflito..., cit.

${ }^{14}$ Nuno Gonçalo Monteiro, O Crepúsculo dos Grandes. A Casa e o Património da Aristocracia em Portugal (1750-1832), Lisboa, INCM, 2003.

${ }^{15}$ Cf. Nuno Gonçalo Monteiro, O Crepúsculo..., cit., p. 95.

${ }^{16}$ Para uma definição mais aprofundada de «bens da Coroa» veja-se Nuno Gonçalo Monteiro, O Crepúsculo..., cit.,p. 243 e seguintes. O arrolamento dos bens patrimoniais, tanto livres como vinculados, que após a extinção da Casa não foram incorporados na Coroa mas entregues à Casa de Lavradio, podem ser consultados em Luís Bivar Guerra, Inventário e sequestro da Casa de Aveiro em 1759, Lisboa, Edições do ATC, 1952.

${ }^{17}$ Assim chamadas «por terem sido do Infante D. Pedro, Duque de Coimbra» - cf. António Caetano de Sousa, História Genealógica da Casa Real Portugueza, T. 11, Lisboa, Na Regia Officina Sylviana, 1742, p. 50. Sobre a Casa e Estado do Infante D. Pedro, vide Humberto Baquero Moreno, "O Infante D. Pedro e o Ducado de Coimbra", Revista de História, 5 (1983-1984). 
representavam percentualmente pouco mais de metade dos rendimentos de quarenta casas de Grandes, o valor resultante dos bens da Coroa administrados pela Casa de Aveiro perfazia quase $90 \%{ }^{18}$. Mas também devido à importância simbólica que revestiam, por exemplo, as terras do Infantado, cuja memória de terem pertencido ao Infante D. Pedro podia ser utilizada como argumento em favor dos duques de Aveiro quando se tratava de reclamar à Coroa as mesmas formas de tratamento de que gozava a Casa de Bragança ${ }^{19}$.

Sobre a Casa de Aveiro existem poucos estudos. Dispomos da importante obra de António Caetano de Sousa, que nos apresenta uma visão global da história dos duques de Aveiro e da sua evolução, referindo algumas doações e senhorios e fazendo uma incursão pelos ramos secundários da linhagem Lencastre $^{20}$. Durante o século passado, foram ainda dados à estampa um conjunto de trabalhos relativos à história da Casa de Aveiro, mas que infelizmente se limitaram à apresentação das diversas linhas de sucessão. São, entre si, de valor diverso. Se, por exemplo, o artigo de Francisco Ferreira Neves se apresenta bastante imparcial, e até interessante por oferecer referências a vários documentos relativos à intervenção dos duques na vila de Aveiro ${ }^{21}$, o mesmo

${ }^{18}$ Resultantes da soma dos rendimentos dos bens da Coroa $(66,07 \%)$ com o das comendas $(23,44 \%)$, que se contrapõem à fraca expressividade do rendimento dos bens patrimoniais $(10,49 \%)$ - cf. Nuno Gonçalo Monteiro, O Crepúsculo..., cit., p. 261-263.

${ }^{19}$ Quando em 1584 D. Filipe II promulgou a Lei das Cortesias, reservou o tratamento de Excelência aos infantes e aos duques de Bragança, o que incitou o duque de Aveiro a mover uma petição reclamando a mesma dignidade. Numa carta enviada para Madrid, D. Álvaro argumentava que a sua Casa, embora tivesse origem na última vontade do rei D. João II, era a continuação natural da Casa e Estados do Infante D. Pedro, $1^{\circ}$ duque de Coimbra: «la qual Casa extinta por muerte del Infante, el rey Don Juan $2^{\circ}$ su nieto la torno a lebantar, dejando en su testamento al maestre su hijo, hecho duque de Coymbra, y señor de las tierras del Infantado»; o que fazia, argumentava, com que a Casa de Bragança devesse à de Aveiro a sua existência: «pues bien se ve la ventaja, y dignidade que haçe el Ynfante Don Pedro a Don Alonso primer duque de Bergança, siendo el primer hermano lixitimo del rey Don Duarte, y el segundo ylejitimo, y havido antes del rey Don Juan su padre lo ser, ni esperar serlo: al qual Don Alonso, el mismo Infante Don Pedro duque de Coymbra, siendo governador del reyno [...], le dio a Bergança con titulo de duque de ella, siendo hasta entonçes, solamente conde de Barçelos, de manera, que por esta via debe la Casa de Bergança a la de Abero el titulo de duque, y buena partte de su grandeza» - cf. Biblioteca Nacional de España (Madrid), MSS/1439, fls- 272v-276.

${ }^{20}$ António Caetano de Sousa, História Genealógica..., cit., p. 1-366, e ainda, do mesmo autor, as Provas da Historia Genealogica da Casa Real Portugueza, T. 6, Lisboa, Na Regia Officina Sylviana e da Academia Real, 1742, contendo uma interessante colecção de documentos sobre a Casa de Aveiro.

${ }^{21}$ Francisco Ferreira Neves, "A Casa e o Ducado de Aveiro. Sua origem, evolução e extinção" in Arquivo do Distrito de Aveiro, Vol XXXVIII (1972). 
não se pode dizer dos de Carlos Ary dos $\operatorname{Santos}^{22}$ e de Montalvão Machado ${ }^{23}$, ambos visivelmente apologéticos e seguindo uma linha de argumentação que procurava legitimar a reabilitação da Casa de Aveiro em favor de presumíveis herdeiros.

Mais recentemente, João Cordeiro Pereira apresentou a caracterização dos rendimentos da Casa de Aveiro em torno do primeiro terço do século XVI ${ }^{24}$, e Sérgio Cunha Soares, num estudo sobre as vereações da vila da Lousã e a sua relação com a Casa de Aveiro, ofereceu-nos a imagem de uma forte capacidade interventiva dos duques sobre esta sua terra ${ }^{25}$, que entretanto Maria do Rosário Castiço de Campos confirmou ${ }^{26}$. São de facto estes estudos sobre os senhorios dos duques que nos oferecem algumas informações importantes sobre a Casa de Aveiro, nomeadamente no que se refere ao exercício dos poderes sobre as terras de que eram donatários.

Pelas doações de 27 de Maio de 1500 D. Jorge de Lencastre, duque de Coimbra, recebeu «todas as jurisdiçoins de Civel, e Crime mero mistico imperio, asi e taõ compridamente como nos todo avemos e de dereito e de feito devemos aver» ${ }^{27}$. Cerca de meio século depois, D. João de Lencastre, $1^{\circ}$ duque de Aveiro e filho de D. Jorge, obteve o mesmo privilégio sobre as terras de Santiago. Porém, as prerrogativas gozadas pelos duques ao tempo da extinção da sua Casa não haviam sido concedidas em conjunto, de uma vez só, mas sim a título isolado e ao longo dos anos da sua existência, conforme a necessidade de doação que, tal como determinavam as Ordenações Manuelinas, esclarecidamente validasse o exercício de determinados direitos jurisdicionais ${ }^{28}$.

${ }^{22}$ Carlos Ary dos Santos, "Estudos de Direito Nobiliárquico Português II. A Sucessão da Casa e Ducado de Aveiro" in Armas e Troféus, VIII (1967).

${ }^{23}$ J. T. Montalvão Machado, Casa e Ducado de Aveiro e sua representação actual, Lisboa, Edição do Autor, 1971.

${ }^{24}$ João Cordeiro Pereira, "A renda de uma grande Casa senhorial de Quinhentos" in Actas das Primeiras Jornadas de História Moderna, vol. 2, Lisboa, CHUL, 1986.

${ }^{25}$ Sérgio Cunha Soares, "O ducado de Aveiro e a vila da Lousã no século XVIII (1732-1759)" in Arunce: Revista de Divulgação Cultural, 11/12 (1996-1997),

${ }^{26}$ Maria do Rosário Castiço de Campos, A Lousã no século XVIII. Redes de Sociabilidade e de Poder. Coimbra: Palimage, 2010.

${ }^{27}$ António Caetano de Sousa, Provas..., T. 6, cit., p. 2-6.

${ }^{28}$ António Manuel Hespanha, As vésperas do Leviathan. Instituições e poder político. Portugal: séc. XVII, Coimbra, Livraria Almedina, 1995, p. 394. Referem as Ordenações que «os Duques, Mestres das Ordens, [...] e pessoas que de Nós [tiverem] Terra com jurisidiçam, usaram della como por suas doações per Nós confirmadas expressamente lhe for outorgado» (L. II, T. 26) - cf. Ordenaçoens do Senhor Rey D. Manuel, Coimbra, Na Real Imprensa da Universidade, 1797, p. 110-111. O resumo de alguns dos privilégios e direitos jurisdicionais da 
O primeiro privilégio expressamente doado à Casa de Aveiro data de Setembro de 1501. Circunscrevia-se às jurisdições de espaço «intermédio» ${ }^{29}$ : a isenção de correição régia ${ }^{30}$; privilégio ao qual se seguiu a concessão do direito de correição senhorial $^{31}$, ampliando-se a sua alçada, em 1556, quando D. João III concedeu a jurisdição crime sobre os roubos e assassinatos ${ }^{32}$. Com o decorrer do tempo foram constituídas duas ouvidorias: a de Azeitão, que superintendia os feitos das terras da Ordem de Santiago; e a de Montemor-o-Velho, que tutelava os assuntos locais das terras do Infantado e da vila de Torres Novas ${ }^{33}$, ambas suprimidas após a extinção da Casa de Aveiro $^{34}$.

A Casa detinha, igualmente, direitos jurisdicionais a nível local, designadamente o provimento de ofícios locais e a nomeação das vereações e de outros oficiais camarários. Em 1556, D. João III doou a D. João de Lencastre o privilégio «de juro e erdade para todos seus erdeiros e deçemdemtes a quem sua casa vier e a erdarem que hos juizes e tabballiaans de suas terras se chamem por elles» ${ }^{35}$. Embora esta prerrogativa se limitasse a possibilitar a nomeação de indivíduos para ofícios de menor importância (juízes de órfãos, juízes de direitos reais e tabeliães), como já foi notado em estudos sobre o poder municipal em Coimbra, Lousã e Penela, este privilégio traduzia-se numa capacidade de criar uma rede clientelar local que serviu de base de recrutamento das vereações ${ }^{36}$.

Casa de Aveiro que referiremos pode ser consultado na Biblioteca Geral da Universidade de Coimbra, Manuscritos, 502.

${ }^{29}$ Sobre este assunto, vide Nuno Gonçalo Monteiro, Elites e Poder..., cit., p. 19-36.

${ }^{30}$ Arquivo Nacional Torre do Tombo, Chancelaria de D. Manuel, Livro 6, fl. 104.

${ }^{31}$ ANTT, Livro 1 de Místicos, fl. 235v-236.

32 ANTT, Corpo Cronológico, Maço 98.

${ }^{33}$ Sobre esta ouvidoria no contexto da reforma administrativa encetada por D. João III que criou a comarca de Aveiro, depois trasladada para a Esgueira e finalmente incorporada na de Coimbra, vide António de Oliveira, A vida económica e social de Coimbra de 1537 a 1640, T. I, Tese de doutoramento em História Moderna e Contemporânea publicada em Biblos: Revista da Faculdade de Letras, XLVII (1971), p. 11-15.

${ }^{34}$ Relativamente à de Montemor-o-Velho, uma provisão do Desembargo do Paço, datada de a 19 de Setembro de 1760, anexou-a à comarca de Coimbra e transferiu algumas das vilas até então sob sua jurisdição para a de Aveiro, vila que se elevava a cidade e se tornava sede de comarca - Arquivo Histórico Municipal de Coimbra, Cartas e Ordens à Câmara (1526-1778), fl. 80 .

${ }_{35}$ ANTT, Chancelaria de D. João III, Livro 46, fls. 171v-172.

${ }^{36}$ Sérgio Cunha Soares, O Município de Coimbra da Restauração ao Liberalismo, vol. II: Sociologia do Poder Municipal, Coimbra, CHSC, 2002, p. 283-394; "O ducado de Aveiro...", cit.; Cristóvão Mata, O concelho de Penela..., cit., p. 88-106. 
Relativamente ao direito de nomearem juízes de fora, os duques de Aveiro não o exerceram a partir do mesmo momento em todos os seus territórios ${ }^{37}$. Se, por exemplo, as vilas de Penela e da Lousã, que partilhavam a mesma judicatura ${ }^{38}$, conheceram o seu primeiro juiz de fora somente a partir do último quartel do século XVII ${ }^{39}$, em 1758 as câmaras das vilas de Abiul $^{40}$ e de Pereira ${ }^{41}$ eram ainda encabeçadas por juízes ordinários, enquanto a Câmara de Aveiro era presidida por um juiz de fora desde pelo menos $1555^{42}$.

Sobre as vereações e o papel desempenhado pelos duques na sua composição, importa ter em atenção a legislação promulgada a respeito do provimento das justiças locais. As Ordenações Filipinas determinavam o método segundo o qual se nomeariam os juízes ordinários, vereadores e procuradores do concelho. «Os homens bons e povo, chamado a concelho» elegiam seis homens para, aos pares, elaborarem três listas com os nomes das pessoas «necessarias para servirem os ditos Oficios tres annos», a partir das quais o juiz mais velho seleccionaria os homens «que mais vozes tiverem», inscrevendo os respectivos nomes numa pauta final da qual seriam eleitos anualmente os juízes ordinários, vereadores e procuradores do concelho: «e esta eleição farão os juizes, quando o corregedor não for presente na cidade, ou vila, em que se houver de fazer: porque sendo presente, a elle pertence fazel-a, e apurar os juizes e Officiaes

${ }^{37}$ Como aliás ocorria nas terras da Casa de Bragança, cujos primeiros juízes de fora foram conduzidos sensivelmente a partir de meados do século XVI, mas não conjuntamente: Barcelos, Bragança e Chaves (1549); Vila Viçosa (1551); Alter do Chão, Arraiolos, Borba e Monsaraz (1567) e Monforte (antes de 1579) - cf. Mafalda Soares da Cunha, A Casa de Bragança ..., cit., p. 230 .

${ }^{38}$ Sérgio Cunha Soares, "O ducado de Aveiro...", cit., p. 68 e Maria do Rosário Castiço de Campos, A Lousã..., cit., p. 35-36, n. 21.

${ }^{39}$ Embora se mencione que o primeiro juiz de fora de Penela (e da Lousã) foi empossado em 1682, a primeira referência documental de que dispomos data de 1692. Todavia, é de crer que após 1673, ano do falecimento do $5^{\circ}$ duque de Aveiro, paralelamente à transferência das nomeações dos oficiais camarários para a Coroa, se tenha operado uma reconfiguração do senado penelense, introduzindo-se então a judicatura em causa. Este oficial foi inicialmente nomeado pela Coroa, tendo a vila de Penela conhecido o seu primeiro juiz de fora nomeado pelo duque somente em 1734 - cf. Cristóvão da Mata, O concelho de Penela ..., cit., p. 55-56.

${ }^{40}$ ANTT, Dicionário Geográfico..., cit., vol. 1, fl. 100.

${ }^{41}$ ANTT, Dicionário Geográfico..., cit., vol. 28, fl. 1048.

${ }^{42}$ Ano de que data uma carta pela qual o duque D. João se dirige «a vos juiz de fora vereadores e procurador do concelho da dita minha villa d'Aveiro», citada por Francisco Ferreira Neves, "A Casa e Ducado...", cit., p. 24. 
per si só. A qual eleição o Corregedor poderá fazer em qualquer tempo do derradeiro da eleição passada» (L. I, T. 67) ${ }^{43}$.

Em 1611, um alvará destinado às «Villas, e logares deste Reino, cujas eleições de Juizes, e Officiaes das Camaras» pertenciam a donatários confirmava o método descrito nas Ordenações, introduzindo apenas algumas especificações relativas à necessidade de os ouvidores se informarem sobre os elegíveis para os ofícios da Câmara, de se acautelarem perante os jogos de interesse dos grupos locais e de estarem atentos quanto a possíveis práticas de suborno ${ }^{44}$. No ano da Aclamação, um novo regimento viria a confirmar as instruções anteriores, mas também a impor o registo das informações biográficas e das capacidades pessoais dos elegíveis ${ }^{45}$. Por fim, um terceiro documento (8 de Janeiro de 1670) estabeleceu definitivamente o processo de eleição das justiças locais: manteve em vigor o título sessenta e sete do primeiro livro das Ordenações Filipinas e reiterou a imperatividade de os ouvidores se acautelarem relativamente a práticas menos honestas ${ }^{46}$.

A actuação do ouvidor de Montemor-o-Velho nas vilas de Penela e da Lousã parece relacionar-se com as diferentes modalidades pelas quais efectivamente se procedia à nomeação das justiças pela parte do donatário: a nomeação definitiva das justiças (dada); a nomeação sujeita a confirmação do Desembargo do Paço (apresentação); e eleição pelas gentes do concelho ratificada pelo seu senhor (confirmação) ${ }^{47}$. Num primeiro momento, os duques ter-se-ão limitado a confirmar as eleições locais, passando depois a gozar do direito de dada de ofícios. A mudança do alcance da prerrogativa ocorreu nos primeiros anos da Restauração - quando no século XVIII foi concedido este direito a D. Raimundo, referiu-se que era doado «na forma que se continha na carta de doação [...] dos senhores reys D. João o $4^{\circ}$ e D. Affonso o $6^{\circ} \gg^{48}-$ e detecta-se na vila de Penela.

No primeiro ano em que se regista a chegada e a abertura das pautas das justiças (1641), é referida a «carta de Sua Excelência de comfirmaçam dos

${ }^{43}$ Cândido Mendes de Almeida, Codigo Philippino ou Ordenações e Leis do Reino de Portugal recopiladas por mandado d'El-Rey D. Philipe I, Rio de Janeiro, Tipografia do Instituto Filomático, 1870, p. 154-155.

${ }^{44}$ José Justino de Andrade Silva, Collecção Cronologica da Legislação Portuguesa, T. I, Lisboa, Na Imprensa de J. J. A. Silva, 1856, p. 314-316.

${ }^{45}$ José Justino de Andrade Silva, Collecção Cronologica..., T. V, cit., p. 228-230.

${ }^{46}$ José Justino de Andrade Silva, Collecção Cronologica..., T. VIII, cit., p. 176-177.

${ }^{47}$ António Manuel Hespanha, As vésperas..., cit., p. 398.

${ }^{48}$ ANTT, Registo Geral das Mercês, Mercês de D. João V, Livro 23, fl. 357. 
oficiais que ham de servir» ${ }^{49}$. As pautas recebidas pela Câmara a partir de 1645 mencionam que os duques de Aveiro mandavam servir ${ }^{50}$. No período durante o qual os oficiais da Câmara foram nomeados pela Coroa (1673- 1732), a fórmula empregue foi a mesma: Sua Majestade mandava, ordenava ou havia por bem que determinado indivíduo servisse de vereador ou procurador do concelho ${ }^{51}$. $\mathrm{O}$ ano de 1733 marcou a retoma da constituição dos mandatos por iniciativa ducal e das pautas enviadas por D. Gabriel de Lencastre constava que os indivíduos eram «eleitos» ${ }^{52}$. Na década de 1750 , cujas pautas conhecemos somente a partir de 1754 , manteve-se o mesmo princípio: os oficiais eram «nomeados» por D. José de Mascarenhas ${ }^{53}$.

A interpretação que fazemos destas passagens é a de que, num primeiro momento, os duques limitaram-se a confirmar as eleições locais, embora as submetessem à avaliação do ouvidor ${ }^{54}$. A partir da década de 1640, a Casa de Aveiro continuou a regular as eleições locais mediante o seu ouvidor, mas passou a deter o privilégio de dada dos ofícios camarários, podendo nestas circunstâncias, como sugere o caso da Lousã ${ }^{55}$, nomear indivíduos cujos nomes não constavam das pautas. Infelizmente, as hipóteses que avançamos são bastante inconclusivas pois reportam-se a um período bastante tardio e somente a dois concelhos do conjunto de terras da Casa de Aveiro que, como veremos, é bastante heterogéneo.

Há uma primeira característica que define a globalidade das terras dos duques de Aveiro: a sua dispersão territorial. Este aspecto da organização espacial do regime senhorial já foi realçado de uma forma geral ${ }^{56}$, e entretanto confirmado por estudos de índole particular ${ }^{57}$. Confirma-se, portanto, no caso das terras da

${ }^{49}$ Centro de Estudos de História Local e Regional Salvador Dias Arnaut (Penela), Livro de Actas de Sessões da Câmara (1640-1641), fl. 86v.

${ }^{50}$ CEHLRSDA, Livro de Actas de Sessões da Câmara (1644-1645), fl. 121 e Livro de Actas de Sessões da Câmara (1670-1673), fls. 26v, 66v e 108.

${ }^{51}$ CEHLRSDA, Livro de Actas de Sessões da Câmara (1715-1727), fls. 33, 65v, 91v, 116, 140v, 170, 190, 220, 242, 279 e 31.

${ }^{52}$ CEHLRSDA, Livro de Actas de Sessões da Câmara (1727-1736), fls. 131v, 156 e 389.

${ }^{53}$ CEHLRSDA, Livro de Actas de Sessões da Câmara (1752-1761), fls. 16, 60, 105v, 144v e185v.

${ }^{54}$ Cristóvão da Mata, O concelho de Penela ..., cit., p. 52 e 58-59.

${ }^{55}$ Sérgio Cunha Soares, "O ducado de Aveiro...", cit., p. 46.

${ }^{56}$ António de Oliveira Marques, "Senhoria” in Joel Serrão (Coord.), Dicionário de História de Portugal, vol. 5: Paróquia-Sinta, Porto, Livraria Figueirinhas, 2002, p. 531-532.

${ }^{57}$ Mafalda Soares da Cunha, A Casa de Bragança..., cit., p. 204-209; Margarida Sobral Neto, Terra e Conflito..., cit., p. 17-27; e Fernando Taveira da Fonseca, A Universidade de Coimbra..., cit., p. 560-562. 
Casa de Aveiro, quer globalmente, quer observando-se especificamente os dois principais núcleos que a compunham. Não obstante tratarmos o património da Casa de Aveiro sob a designação geral de bens da Coroa, este organizava-se em dois núcleos distintos dispostos geograficamente em função da sua natureza: os bens das ordens militares e os (efectivos) bens da Coroa.

A criação da Casa de Aveiro consumou-se formalmente a 27 de Maio de 1500, quando D. Manuel, cumprindo as cláusulas testamentárias de D. João II ${ }^{58}$, doou a D. Jorge de Lencastre as terras do Infantado ${ }^{59}$. Mas D. Jorge dispunha de um outro conjunto de bens recebido de D. João II, que simultaneamente podia supor uma vantagem simbólica sobre a Casa de Bragança ${ }^{60}$ e garantia uma importante fonte de rendimentos ${ }^{61}$ : o mestrado da Ordem de Santiago e o governo e administração da Ordem de Avis ${ }^{62}$. Com o decorrer do tempo, D. João III veio a incorporá-las definitivamente na $\mathrm{Coroa}^{63}$, mas nem por isso os sucessores de D. Jorge perderam a ligação à Ordem de Santiago.

Na qualidade de administrador desta ordem, D. Jorge doou a D. João de Lencastre, seu primogénito e $1^{\circ}$ duque de Aveiro, as comendas de Aljustrel, Arrábida, Arruda, Belmonte, Barreiro, Castro Verde, Ferreira, Samora Correia, Santiago do Cacém, Sesimbra e Sines. «E supposto os Commendadores das referidas Commendas eraõ Alcaides mores dellas, El-Rey [D. João III] the fez merce de lhe dar jurisdição de todas aquelas Villas, de que ficou sendo Senhor ${ }^{64}$. Mantinha, portanto, os bens da Ordem de Santiago, embora sob uma

${ }^{58}$ António Caetano de Sousa, Provas..., T. 2, cit., p. 172-73.

${ }^{59}$ António Caetano de Sousa, Provas..., T. 6, cit., p. 1-3.

${ }^{60} \mathrm{O} 4^{\mathrm{o}}$ duque de Bragança, D. Jaime, requereu que os bens e rendas de quinze igrejas sobre as quais exercia direito de padroado fossem transformados em comendas da Ordem de Cristo, alegando que necessitava da mercê para recompensar os serviços dos seus criados. A escolha por esta Ordem, e não pela de Avis ou de Santiago, explica Mafalda Soares da Cunha, devia-se sobretudo ao facto de ser a de «maior capital de prestígio social», mas também por se encontrar «fora da jurisdição de D. Jorge de Lencastre, duque de Coimbra. Na complexa teia da simbólica do poder social de então, compreende-se que a Casa de Bragança não se prestasse à subalternização que constituiria ver as suas nomeações confirmadas por D. Jorge na sua qualidade de mestre das Ordens de Santiago e de Avis.» - cf. Mafalda Soares da Cunha, A Casa de Bragança..., cit., p. 312-313.

${ }^{61}$ Em 1527, por exemplo, rendiam à Casa de Aveiro a totalidade de 3.992 .000 reais e 3.882.000 reais - João Cordeiro Pereira, “A renda de uma grande casa..., cit., p. 885-898.

${ }^{62}$ António Caetano de Sousa, Historia Genealógica..., T. 11, cit., p. 5.

${ }^{63}$ A 25 de Agosto de 1550, D. João III obteve autorização papal para herdá-las do duque de Coimbra e, no mês seguinte, a bula Praeclara Charissimi in Christo concedia a administração perpétua das duas ordens à Coroa - cf. ANTT, Gaveta 5, Maços 1 e 3.

${ }^{64}$ António Caetano de Sousa, Historia Genealógica..., T. 11, cit.,p. 50. Desconhecemos em que data foi feita a doação, assim como o ano em que D. João III concedeu ao duque de Coimbra 
forma distinta da que inicialmente o pai recebera, e porque a uma comenda não correspondia obrigatoriamente a jurisdição da terra ${ }^{65}$, a posterior mercê de D. João III duplicava-lhes a natureza.

Numa relação das comendas desta ordem e dos respectivos rendimentos elaborada em 1572, mencionam-se apenas algumas daquelas terras (rendendo 3.750 .000 réis $)^{66}$. Mas em 1668, quando D. Pedro de Lencastre, $5^{\circ}$ duque de Aveiro, obteve sentença favorável sobre o processo de sucessão, eram referidas as mesmas terras constantes do arrolamento ${ }^{67}$; à data da extinção da Casa, o último duque não possuía estas terras. D. José de Mascarenhas havia herdado a Casa e o Ducado, mas não os bens «que pertenciaõ às Ordens, por haver de ser por cartas passadas pelo Tribunal da Mesa da Consciencia, e Ordens ${ }^{68}$. Por ocasião da elaboração das Memórias Paroquiais, ou seja, um ano antes da extinção da Casa, as respostas relativas à existência ou não de donatário das vilas indicam que a as respectivas terras eram da Casa de Aveiro, mas encontravam-se sob administração régia: o pároco de Castro Verde, por exemplo, afirmava que era do Duque de Aveiro ${ }^{69}$, e o do Torrão o mesmo, acrescentando apenas que «de presente [é] de Sua Magestade» ${ }^{70}$.

A caracterização do território onde se implantavam os bens da Ordem de Santiago revela, portanto, o que acima afirmámos: nomeadamente, a dispersão espacial das terras que compunham este núcleo. Conforme se verifica no quadro abaixo exposto, todas elas se localizavam nas províncias da Estremadura e, com maior incidência, do Alentejo, repartindo-se pelos arcebispados de Lisboa e Évora, variando a sede das comarcas e provedorias a que pertenciam entre Setúbal, Ourique e Beja, enquanto ao nível da jurisdição senhorial todas estavam subordinadas à ouvidoria de Azeitão.

os senhorios das referidas terras, embora estes devessem ter sido transferidos após o falecimento de D. Jorge. Na já citada carta que enviou a D. Filipe II, D. Álvaro referia que «bacando por su muertte para la Corona los maestrazgos con todas sus villas, que san muchos, y viendo el rey Don Juan $3^{\circ}$ que el duque de Abeyro [...] quedava con menos villas, que el de Verganza dijo publicamente que lo sentia mucho, y que deseava poderle hacer en esta parte ygualdad, y en efecto trato de darle (como dio) la jurisdicion de las villas de las encomiendas» - cf. BNE, MSS/1439, fls. 277-277v.

${ }^{65}$ Fernanda Olival, "As Ordens Militares e o poder local: problemas e perspectivas de estudo" in Mafalda Soares da Cunha e Teresa Fonseca (Ed.), Os Municípios..., cit., p. 109.

${ }^{66}$ ANTT, Gaveta 5, Maço 1.

${ }^{67}$ Francisco Ferreira Neves, “A Casa...", cit., p. 111-112.

${ }^{68}$ António Caetano de Sousa, Memorias Historicas, e Genealogicas dos Grandes de Portugal, Lisboa, Na Regia Officina Sylviana e da Academia Real, 1755, p. 26.

${ }^{69}$ ANTT, Dicionário Geográfico de Portugal, vol. 10, fl. 1521.

${ }^{70}$ ANTT, Dicionario Geografico..., vol. 36, cit., fls. 595 
Quadro 1 - Bens da Ordem de Santiago no século XVIII ${ }^{71}$

\begin{tabular}{|c|c|c|c|c|c|c|}
\hline Terra & Concelho & Província & $\begin{array}{c}\text { (Arce) } \\
\text { Bispado }\end{array}$ & Comarca & Provedoria & Ouvidoria \\
\hline Barreiro & Sede & Estremadura & Lisboa & Setúbal & Setúbal & Azeitão \\
\hline Castro Verde & Sede & Alentejo & Évora & Ourique & Ourique & Azeitão \\
\hline Ferreira & Sede & Alentejo & - & Beja & - & [Azeitão] \\
\hline Samora Correia & Sede & Estremadura & Lisboa & Setúbal & Setúbal & Azeitão \\
\hline Santiago do Cacém & Sede & Alentejo & - & Ourique & - & [Azeitão] \\
\hline Sesimbra & Sede & Estremadura & - & Setúbal & Setúbal & Azeitão \\
\hline Sines & Sede & Alentejo & Évora & Ourique & Ourique & Azeitão \\
\hline Torrão & Sede & Alentejo & Évora & Beja & Beja & Azeitão \\
\hline
\end{tabular}

Esta descontinuidade territorial do património da Casa de Aveiro acentua-se ainda mais se evocarmos aquele núcleo que constituía, a nível simbólico e material, o mais importante conjunto de bens doados pela Coroa. Para além de se situarem geograficamente numa zona bastante distinta e longínqua dos senhorios e comendas da Ordem de Santiago, as terras do Infantado distribuíam-se de uma forma bastante dispersa ao longo de um eixo estendido entre as vilas de Aveiro e Torres Novas. Como demonstra o quadro abaixo apresentado, estas terras situavam-se nas duas províncias da região centro do Reino (Estremadura e Beira), todas pertenciam à mesma diocese (Coimbra), mas repartiram-se pelas corregedorias e provedorias da Esgueira, Coimbra e Tomar. Possivelmente em virtude da sua centralidade, Montemor-o-Velho foi sede de ouvidoria, a cuja correição, de resto, todos estes lugares estavam sujeitos, sendo Torres Novas um caso único, tanto por estar sujeita à provedoria de Santarém, como por não ser parte integrante do conjunto de terras do Infantado ${ }^{72}$.

${ }^{71}$ Com base em ANTT, Dicionario Geografico..., cit., vol. 6, fls. 535-537; vol. 10, fls. 1521-1526; vol. 35, fls. 1311-1326; vol. 36, fls. 595-606; vol. 42, fl. 54; e António Carvalho da Costa, Corografia Portugueza, e descripçam topografica do famoso reyno de Portugal, T. 2, Lisboa, Na Officina Real Deslandeana, 1712, p. 484-486, 496-497, 503, 506; e, no T. 3 , p. 321, 327-328, 504-505.

${ }^{72}$ Apesar de as doações das terras do Infantado e da vila de Torres Novas datarem do mesmo dia, a sua outorga formalizou-se mediante a lavra de dois documentos diferentes, o que significa a existência de núcleos de bens da Coroa distintos. É o que sugere o contrato de casamento celebrado por D. Jorge de Lencastre e D. Brites de Vilhena, que hipotecava a vila de Torres Novas «com todo o que nella tem» e não nenhuma terra do Infantado, se tivermos em conta o princípio da indivisibilidade do património. Há ainda um outro indício, que não cremos tratar-se de uma mera questão de semântica: enquanto a Casa de Aveiro esteve sob a administração da Coroa (1673-1732), as suas terras continuaram a ser visitadas por ouvidores das vilas do ducado de 
Quadro 2 - Terras do Infantado e vila de Torres Novas no século XVIII ${ }^{73}$

\begin{tabular}{|c|c|c|c|c|c|c|c|}
\hline Terra & Donatário & Concelho & Província & Bispado & Comarca & Provedoria & Ouvidoria \\
\hline Abiul & C. Aveiro & Sede & Estremadura & Coimbra & - & Tomar & Montemor-o-Velho \\
\hline Águeda & C. Aveiro & Aveiro & Beira & Coimbra & Esgueira & - & Montemor-o-Velho \\
\hline Ansião & {$[-]$} & Sede & - & - & Coimbra & - & - \\
\hline Aveiro & C. Aveiro & Sede & Beira & Coimbra & Esgueira & - & Montemor-o-Velho \\
\hline Avelãs de Cima & - & Sede & Beira & Coimbra & Esgueira & - & [Montemor-o-Velho] \\
\hline Bolfiar & [C. Aveiro] & Sede & - & - & - & - & [Montemor-o-Velho] \\
\hline Brunhido & C. Aveiro & Sede & - & Coimbra & - & - & Montemor-o-Velho \\
\hline C. de Álvaro & [C. Aveiro] & Sede & - & - & - & - & Montemor-o-Velho \\
\hline Coimbra & Coroa & Sede & Beira & Sede & Sede & Sede & [Montemor-o-Velho] \\
\hline Condeixa & Coroa & Coimbra & Beira & Coimbra & Coimbra & - & [Montemor-o-Velho] \\
\hline Esgueira & M. Lorvão & Sede & Beira & Coimbra & Sede & - & [Montemor-o-Velho] \\
\hline Ferreiros & [C. Aveiro] & Sede & - & Coimbra & - & - & [Montemor-o-Velho] \\
\hline Lousã & C. Aveiro & Sede & Beira & Coimbra & Coimbra & - & Montemor-o-Velho \\
\hline Miranda do Corvo & C. Lafões & Sede & - & - & Coimbra & - & [Montemor-o-Velho] \\
\hline $\begin{array}{l}\text { Montemor-o- } \\
\text {-Velho }\end{array}$ & C. Aveiro & Sede & Beira & Coimbra & - & - & Sede \\
\hline Penela & C. Aveiro & Sede & Estremadura & Coimbra & Coimbra & Tomar & Montemor-o-Velho \\
\hline Pereira & C. Aveiro & Sede & Beira & Coimbra & Coimbra & - & Montemor-o-Velho \\
\hline Recardães & C. Aveiro & Sede & Beira & Coimbra & Esgueira & Esgueira & Montemor-o-Velho \\
\hline Segadães & C. Aveiro & Sede & Beira & Coimbra & Esgueira & Esgueira & Montemor-o-Velho \\
\hline Serpins & M. Lorvão & Sede & Beira & - & Coimbra & - & [Montemor-o-Velho] \\
\hline Torres Novas & C. Aveiro & Sede & Estremadura & Lisboa & - & Santarém & Montemor-o-Velho \\
\hline
\end{tabular}

A apresentação destes dois quadros confirma, pois, a tendência verificada na distribuição geográfica dos rendimentos que a Casa de Aveiro auferia no ano de 1759: a (quase) concentração dos bens da Coroa nas regiões centro e sul do país, embora quantitativamente a Beira (46\%) perfizesse ligeiramente menos

Aveiro, das terras do infantado da cidade de Coimbra e da vila de Torres Novas - vide Cristóvão da Mata, $O$ concelho de Penela..., cit., p. 50. Ambas as doações, bem como o referido contrato de casamento, podem ser consultados em António Caetano de Sousa, Provas..., T. 6, cit., p. 1-7 e 9-16.

73 A partir de ANTT, Dicionário Geográfico..., cit., vol. 1, fls. 93-110 e 385-394; vol. 5, fls. 799-820 e 839-842; vol. 11, fls. 2371-2399 e 2523-2524; vol. 14, fls. 413-420; vol. 21 , fls. 1305-1312; vol. 24, fls. 1465-1498; vol. 28, fls. 1045-1052; vol. 31, fls. 169-174; vol. 34, fls. 779-784 e 1029-1035; vol. 42, fls. 9 e 91; e António Carvalho da Costa, Corografia Portuguesa..., cit., T. 2, p. 98, 114, 143, 151, 162; e T. 3, p. 227. 
do que a soma dos rendimentos provenientes da Estremadura $(26,04 \%)$ e do Alentejo $(25,29 \%)^{74}$. No Alentejo localizavam-se predominantemente as terras da Ordem de Santiago, mas o peso desta província no cômputo geral da geografia dos rendimentos não derivava unicamente do que rendiam as comendas. Muitas das terras com cujos senhorios D. João de Lencastre foi agraciado por D. João III tinham foral ${ }^{75}$, o que significa que, a par das comendas, a Casa de Aveiro arrecadou direitos reais nas suas terras do sul, embora apenas um olhar mais atento sobre o conteúdo destes diplomas possa esclarecer a dimensão dos direitos arrecadados.

Relativamente à Beira, é a amplitude conceptual do termo «bens da Coroa» que contribui para explicar a sua hegemonia na distribuição geográfica dos rendimentos. Como se verifica no quadro atrás exposto, muitas das terras do Infantado que considerámos pertencerem ao património da Casa de Aveiro não tinham os duques de Aveiro como donatários. Aliás, a coincidência entre a origem dos rendimentos e as terras sobre as quais a Casa de Aveiro detinha direitos jurisdicionais era apenas de $40,82 \%$ (mas muito superior à media) ${ }^{76}$.

É disso exemplo a vila de Ansião, cujo foral manuelino concedia ao Mosteiro de Santa Cruz de Coimbra alguns direitos «de senhorio» e a teiga de Abraão à Casa de Aveiro, embora se encontrasse sob a jurisdição cível e crime da Câmara de Coimbra até 1674, ano em que foi desanexada do termo coimbrão, elevada a vila e doada a D. Luís de Meneses, $3^{\circ}$ conde de Ericeira ${ }^{77}$. Do mesmo modo, a cidade de Coimbra não era terra de senhorio dos duques mas ingressara no património da Casa de Aveiro em 1502, quando pela mesma carta com a qual criava o ducado de Coimbra D. Manuel fez a D. Jorge «doaçam e merce do Castelo e Alcaydaria mor da dita nossa Cidade de Coimbra com todas as rendas direitos foros e pertenças a dita Alcaydaria mor ordenados e que de dereito lhe pertencem e assy mesmo dos Padroados das Igrejas que na dita cidade e seu termo tevermos [...] e dos Taballiaes da dita Cidade e termo della

${ }^{74}$ Tanto o Minho com os Açores constam também da primeira lista, embora com uma expressividade quase insignificante: $0,79 \%$ e $1,88 \%$, respectivamente - vide Nuno Gonçalo Monteiro, O Crepúsculo..., cit., p. 275.

${ }^{75}$ Aljustrel, Barreiro, Castro Verde, Ferreira, Samora, Santiago do Cacém, Sesimbra, Sines e Torrão - cf. ANTT, Livro 7 de Odiana, fls. 197-198; Livro de Forais Novos de Entre o Tejo e Odiana, fls. 32v-33v, 45-46, 49-49v, 79-79v, 86-86v, 96v-98v.

${ }^{76}$ Nuno Gonçalo Monteiro, O Crepúsculo..., cit., p. 287.

${ }^{77}$ Margarida Sobral Neto, O Universo da Comunidade Rural. Época Moderna, Coimbra, Palimage, 2010, p. 123-148. 
e penções delles» ${ }^{78}$. Em ambos os casos, tratava-se de direitos reais fixados nos forais manuelinos.

Por outro lado, a coincidência do exercício das jurisdições com as fontes de rendimento incidia precisamente nas terras onde os duques cobravam direitos reais ${ }^{79}$. As referências a fontes de rendimento que abundantemente se encontram dizem respeito a bens da Coroa, embora a sua forma concreta pudesse variar. Durante o longo período de vacância na administração da Casa de Aveiro (1673-1732) foi ordenado pela Coroa a elaboração de tombos sobre «as terras e propriedades pertencentes à Casa Real e Casa de Aveiro sua donataria $»^{80}$. Desta ordem resultou uma longa série de livros relativos a um conjunto de terras dispostas em torno das vilas de Aveiro e Montemor-o-Velho e da cidade de Coimbra ${ }^{81}$. Os tombos estão organizados de acordo com a estrutura habitual: um apenso de documentos inicial, do qual constam vários traslados de alvarás relativos à realização do tombo e de doações e os autos de juramento tomado pelos oficiais locais; seguido pela demarcação do espaço sob jurisdição da Casa de Aveiro; e finalmente o encabeçamento e reconhecimento dos enfiteutas das terras que possuíam e dos direitos devidos ao donatário ${ }^{82}$.

Encontramos, assim, no primeiro livro do tombo de Casal de Álvaro e Bolfiar a petição endereçada a D. Pedro II por Jorge de França, membro do Conselho de Estado e administrador da Casa, pedindo a autorização necessária para se levar a cabo a avaliação dos senhorios da Casa de Aveiro nas suas terras, assim como o alvará régio (5 de Março de 1692) que ordenava ao Dr. António Duarte de Barros, desembargador do Tribunal da Relação do Porto, que cumprisse o requerido e o nomeava juiz dos tombos ${ }^{83}$ - para o mesmo efeito eram designados um escrivão, um procurador da Coroa e outro da Casa de Aveiro e um medidor. Encontra-se também registado, por exemplo, o traslado de uma sentença obtida

${ }^{78}$ António Caetano de Sousa, Provas..., T. 6, cit., p. 8.

${ }^{79}$ Nuno Gonçalo Monteiro, O Crepúsculo..., cit., p. 288.

${ }^{80}$ Arquivo da Universidade de Coimbra, Livro do Tombo do Casal de Álvaro e Bolfear (1500-1703), fl. 2.

${ }^{81} \mathrm{O}$ registo num destes livros de uma ordem do administrador da Casa de Aveiro para o juiz dos tombos, o Dr. António Duarte de Barros, concluir os tombos das vilas da Lousã, Penela e Torres Novas sugere que a avaliação das terras do Infantado estava a ser feita conjuntamente; infelizmente, estes tombos não integram o fundo documental, pelo que é de crer que se tenham perdido ou até, tendo em conta o teor da ordem, que nunca tenham sido elaborados - cf. AUC, Livro do Tombo do Casal..., cit., fl. 5.

${ }^{82}$ Margarida Sobral Neto, "Reconstituição da vida material de comunidades rurais em contexto senhorial: problemas, fontes e métodos" in Actas do Congresso Maia, História Local e Regional, vol. X, Maia, Câmara Municipal, 1999, p. 111-127.

${ }^{83}$ AUC - Livro do Tombo do Casal..., cit., fls. 2-3v. 
pela Casa de Aveiro relativamente à posse do senhorio jurisdicional. A doação havia sido feita por D. Manuel mas, em virtude de já haver donatário, D. Jorge só «havia de thomar posse quando vagassem por expirar o titolo de quem as trazia e porque Martim Lourenço da Cunha que as ditas terras trazia faleçeo sem filhos nem descendentes lídimos pelo que expirou o titollo e doação feita», concedendo-lhe então D. João III a autorização para tomar posse das terras ${ }^{84}$.

Os tombos demonstram que os bens das terras do Infantado assumiam diversas formas. Na cidade de Aveiro e de Coimbra os bens da Casa de Aveiro eram essencialmente prédios urbanos, enquanto nas terras situadas na vasta zona entre Aveiro e Coimbra os duques possuíam predominantemente prédios rústicos. Também nos fornecem informações sobre o regime de propriedade desses mesmos bens. Sobre Aveiro, por exemplo, foi elaborado «o tombo das rendas e foroz desta dita vila de Aveiro e sua pertenças e se fizeram actos publicos de reconhecimentos das terras e propriedades que cada hum [dos] imphiteutas possue» ${ }^{85}$. Esta passagem evidencia o regime de propriedade em causa, o regime enfiteutico. À Casa de Aveiro pertencia o domínio directo dos bens sendo-lhe devidos pelos possuidores do domínio útil o foro e o laudémio ${ }^{86}$. $\mathrm{Na}$ qualidade de direitos reais, a mesma entidade senhorial cobrava de «todos os vizinhos e moradores da dicta villa que tiverem casas em que sy vivam pessoalmente ora sejam suas ou d'aluguer pagara cada huum hũa galinha e tres reais e meio em dinheiro [...] e se cada hum dos ditos vizinhos e moradores vender todas suas casas que hy tivesse $[\ldots]$ pera per ella aver de pagar o dito foro este tal pagara ao senhorio ${ }^{87}$.

Houve ainda um terceiro conjunto de bens que, pelo menos na sua fase inicial, integrou o património da Casa de Aveiro. Designadamente as terras cuja posse D. João II confirmou a D. Jorge a 7 de Setembro de 1491: por um primeiro documento, a beetria de Amarante, honra de Ovelha e respectivas jurisdições, senhorios, rendas, foros, tributos e serviços ${ }^{88}$; e, por outro, a beetria de Canaveses, o couto de Tivas, cinco honras e a «jurdiçaõ de todalas Villas foros, tributos, servissos ${ }^{89}$. Segundo indicam ambos os documentos, as terras haviam pertencido ao irmão do duque de Coimbra, tendo os habitantes das mesmas, após o falecimento do infante D. Afonso, escolhido D. Jorge como

\footnotetext{
${ }^{84}$ AUC, Livro do Tombo do Casal..., cit., fls. 8v-9v.

85 AUC, Livro Primeiro do Tombo de Aveiro (1380-1693), fl. 3.

${ }^{86}$ Sobre a enfiteuse, veja-se Margarida Sobral Neto, $O$ Universo..., cit., p. 58.

87 ANTT, Livro de Forais Novos da Estremadura, fls. 207v-212v.

${ }^{88}$ António Caetano de Sousa, Provas..., T. VI, cit., p. 16-18.

${ }^{89}$ António Caetano de Sousa, Provas..., T. VI, cit., p. 18-21.
} 
senhor. Os mesmos diplomas não especificavam se as doações eram feitas por uma só vida ou perpetuamente, mas em 1550 , pouco antes do seu falecimento, D. Jorge apresenta-se numa carta ao seu filho D. Luís como «mestre de Santiago, e de Avis, duque de Coimbra, Senhor de Montemor, Torres Novas, e das beatrias, $\& \mathrm{c} »^{90}$.

Posteriormente, não se faz mais referências as estas terras, que assim se distinguem das do Infantado e da Ordem de Santiago não apenas pelo seu estatuto jurídico ${ }^{91}$, mas sobretudo por não terem perdurado na posse da Casa de Aveiro. A 17 de Janeiro de 1759, a confirmação feita por D. José à «effectiva reversão, e actual incorporação na Minha Real Coroa de todos os bens vinculados, que por elles [réus] erão administrados, e possuidos, naquellas partes, em que houvessem sido constituidos em bens da mesma Coroa» ${ }^{92}$ extinguia uma Casa aristocrática usufruidora de poderes jurisdicionais progressivamente reforçados e dotada, igualmente, com um amplo património material cuja importância, um pouco devido ao tardio interesse pelo regime senhorial, mas sobretudo por causa das limitações documentais, não tem sido suficientemente considerada pela historiografia portuguesa.

Recebido em/Text submitted on: 15/01/13

Aceite em/Approved on: 17/05/13

${ }^{90}$ António Caetano de Sousa, Provas..., T. VI, cit., p. 107.

${ }^{91}$ Enquanto as terras do infantado, Torres Novas e as da Ordem de Santiago gozavam de estatuto municipal no seu «tipo mais básico da organização territorial», estas últimas terras eram julgados, beetrias, coutos e honras, isto é, circunscrições administrativas que se distinguem dos concelhos ora por serem somente «terras isentas da jurisdição ordinária» (coutos) ou porque «gozavam da mesma imunidade em virtude da qualidade nobre do seu senhor» (honras), ora por possuírem «o privilégio de elegerem o seu senhor e de o depor» (beetrias) - cf. António Manuel Hespanha, As vésperas..., cit., pp 104-105.

92 António Delgado da Silva, Collecção da Legislação Portugueza desde a ultima compilação das ordenações. Legislação de 1750 a 1762, Lisboa, Typografia Maigrense, 1828, p. 912. 